\title{
Toward an Economic Theory of Leadership: Leading Adaptive Change
}

\author{
Mark A. Jamison ${ }^{1}$
}

Draft Date: June 8, 2006

\begin{abstract}
$\underline{\text { Abstract }}$
This paper develops a model of adaptive leadership, which is leadership that helps organizations adapt to new or existing realities. A manager provides adaptive leadership by exposing the organization to a novel experience that demonstrates that the firm's beliefs do not match reality. Exposure to the novel experience creates distress, which decreases utility for managers and lowers productivity. The prospects for increasing profits by improving beliefs, the desire to decrease distress by engaging in adaptive learning, and the possibility of improving productivity by lowering distress and stimulating controlled cognitive processes motivate managers to engage in adaptive work, which requires effort and consumes resources. If there is no novel experience, managers might engage in interesting work because it stimulates cognitive processes, which improve productivity. Casualties may result from adaptive leadership: Some managers will find the distress too much and leave the firm. The manager practicing adaptive leadership may lose her job if the authority figure finds the novel experience too distressful.
\end{abstract}

\footnotetext{
${ }^{1}$ Director, Public Utility Research Center, and a Lecturer in Economics at the University of Florida, PO Box 117141, Gainesville, Florida 32611-7142, +1.352.392.2929 and jamisoma@ufl.edu. I would like to thank Ron Heifetz and Marty Linsky for teaching me about adaptive leadership. I would also like to thank David Sappington, Sanford Berg, Paul Sotkiewicz, Rich Gentry, Rick Johnson, Dolores Albarricín, Janice Hauge, Lynne Holt, and Florian Englmaier for their suggestions on this research. All mistakes are the responsibility of the author. This is a work in progress. Please do not quote or cite without permission of the author.
}

This is a work in progress. Please do not cite or quote without permission of the author. 


\section{Introduction}

A number of disciplines consider the issue of individual leadership in organizations, including management, psychology, sociology, and political science (Van Fleet, 1975). The theoretical and empirical studies in these fields number in the thousands and, according to some contributors to this literature, the conclusions are diverse, inconclusive, and often contradictory (Yukl and Van Fleet, 1990, p. 147; Bass 1990a, pp. 11-55). Recently economic theories of leadership have emerged. Hermalin (1998) considers a model in which a person signals superior information to her team. Fulton (2001) examines how groups choose authority figures. Rotemberg and Saloner (2000) and Van den Steen (2005) consider the roles of visionaries in directing groups. ${ }^{2}$

Missing from this literature is an economic model of how an individual practicing leadership can help an organization effect an adaptive change. An adaptive change is one in which a group adapts its beliefs, rules, and strategies to its environment, either because the group has become aware that its environment has changed in some significant way, learned something new and significant about its situation, or entered into a new environment. (North, 2005, p. 61) By beliefs we mean the mental constructs that people hold to understand the state of the world. (North 2005, pp. 2-3, 49, 59-70; Heifetz 1994, p. 22) Rules can be formal, such as governmental laws, or informal, such as conventions and culture (North 1990, p. 4). Models are needed that help us understand how and why a person might practice leadership, how and why others might cooperate with this person or resist, and how an organization is changed by the practice of leadership.

This paper seeks to address this gap in the literature by presenting a framework for an economic theory of adaptive leadership in organizations. Building on North (1990 and 2005), Heifetz (1994), and Kotter (1990a, 1990b), we examine leadership as a role whose purpose is to assist an organization to adapt. We consider a model in which a firm's managers choose rules and strategies based on their beliefs about the state of the world. Reality cannot be known with certainty except at an arbitrarily high cost, but the

\footnotetext{
${ }^{2}$ Other relevant economic literature would include that related to principal-agent issues and transaction costs (Sappington, 1991; Williamson and Masten, 1999).
}

This is a work in progress. Please do not cite or quote without permission of the author. 
managers, when confronted with a novel experience, may engage in adaptive work to learn more about reality and to adjust their institutional practices and strategies accordingly. Some managers may resist the novel experience and the adaptive work because they fear ambiguity, wish to avoid the effort of adaptive work, or anticipate experiencing a sense of loss if the firm were to change its institutional arrangements or strategies. (Heifetz, 1994, p. 22; North, 2005, p. 62) For example, a person whose skills make him particularly well suited for directing work in his own country may resist adjusting to doing business in another country whose practices seem strange and hard to comprehend. Persons who seek to challenge existing beliefs and practices and orchestrate the adaptive work are said to be practicing leadership. (Heifetz, 1994, pp. 15-27) ${ }^{3}$

More formally, a person provides adaptive leadership by exposing the organization to a novel experience that demonstrates that the firm's beliefs and rules are insufficient. This creates ambiguity and distress, which people experience as a decrease in utility and which lower productivity. The prospects for increasing profits by improving beliefs and the desire to decrease ambiguity and distress motivate managers to engage in adaptive work. The result of adaptive work is adaptive learning, which is the improving of beliefs to more closely match reality. A manager is more likely to provide adaptive leadership if she expects improved beliefs to increase profits and if the profit increase lasts for more production periods than does the adaptive work. Casualties may result from adaptive leadership: Some managers will find the distress too much and so leave the firm. The manager practicing adaptive leadership may lose her job if the authority figure finds the novel experience too distressful.

The leadership literature considers numerous concepts of leadership (Bass, 1990a), which can be grouped into five approaches [Robbins, 2003, pp. 314-363; Yukl and Van Fleet, 1990; Bass 1990a). The trait approach (Stogdill, 1948) emphasizes the personal characteristics of successful managers, including age, IQ, physical stature, ability to

\footnotetext{
${ }^{3}$ North (2005, p. 60) refers to persons serving in this role as organization entrepreneurs. We omit the term "leader" because the leadership we consider in this paper is a situational, informal role in an organization, not a formal role (Kotter, 1990a, pp. 3-18; Heifetz, 1994, p. 20; Hermalin, 1998; Heifetz and Linsky, 2002). Hereafter, we use the term "managers" to denote the persons who have formal authority roles in organizations. Some authors, such as Fulton (2001), refer to these formal authority figures as leaders.
}

This is a work in progress. Please do not cite or quote without permission of the author. 
communicate, and insightfulness. Although this research identifies traits that can contribute to such a person's success as a manager - for example, high energy, stress tolerance, emotional maturity, self-confidence, and emotional intelligence - no traits are found to consistently cause someone to be successful. (Bass, 1990a; Yukl and Van Fleet, 1990, p. 147; Goleman, 1995, pp. 33-45) Another approach, called the behavioral approach, focuses on the actions of managers. This research examines how managers orient tasks towards a goal, the characteristics of managers' relationships with employees, the extent to which managers are employee-oriented and production-oriented, and how they stimulate new ideas and implement change. (Schriesheim, Cogliser, and Neider, 1995; Blake and Mouton, 1982; Ekvall and Arvonen, 1991)

As its name implies, the power and influence approach examines managers' abilities to influence subordinates, peers, superiors, and outsiders through the use of formal authority, rewards, coercion, and the like. (Yukl and Van Fleet, 1990, pp. 160-161) The situational approach focuses on the context within which managers do their jobs. The literature on this approach includes studies of people's expectations of managers (Kahn, Wolfe, Quinn, and Snoek, 1964) and the effects of the work environment (Hunt and Osborn, 1982; Osborn and Hunt, 1975) on manager success. The transformational and charismatic leadership approach focuses on a person's ability to influence major changes in others' perspectives and assumptions, and on the effects of personal charisma (Weber, 1964 c1947; Bass, 1990b).

Heifetz (1994) and Heifetz and Linsky (2002) depart from these traditions by developing the concept of adaptive leadership and clearly distinguishing between leadership and authority. ${ }^{4}$ In this framework, a person playing an adaptive leadership role calls attention to threats to the organization and assists others in the adaptive work of changing the institution. ${ }^{5}$ In contrast to this adaptive leadership role, Heifetz (1994, pp. 49-66) defines the authority figure as the person who provides direction, orders work, and decreases

\footnotetext{
${ }^{4}$ Hermalin (1998) also distinguishes between leadership and authority.

${ }^{5}$ Adaptive work involves two activities. The first is learning about the state of the world. The second is adapting institutional rules. (Heifetz, 1994, p. 22) Different individuals may perform these activities. In our model, we focus on the first activity and assume the authority figure adapts institutional rules.
}

This is a work in progress. Please do not cite or quote without permission of the author. 
uncertainty and ambiguity by protecting the organization from outside threats. The authority figure and the person providing leadership potentially have conflicting roles.

The economics literature provides several insights into the mechanisms of institutional change. North (1990, p. 3) defines an institution as the rules of the game for a group, which is the definition we adopt for purposes of this paper. Hurwicz (1993) identifies economic models of institutional change that incorporate an institutional rule-setting stage that determines how the institution makes its strategic choices. His model does not provide a clear purpose for an intervener, which is the person or group that initiates an institutional change. North (2005) more fully examines the nature of institutional change. He explains that people base institutional rules on their beliefs about the state of nature and about what others believe. Consistent with Heifetz (1994), North (2005, pp. 59-70) further states that people's abilities to change institutional rules, should a change in beliefs trigger the desire to make such a change, depend on having adaptive skills, which are different from the technical skills that make people effective managers or technical workers. He also holds that adaptive change creates disorder in the short run. Disorder creates ambiguity, which motivates people to learn about their environment and create new rules in accordance with the new beliefs. But the personal cost of ambiguity and the fear of loss lead some people to resist (Heifetz, 1994, pp. 235-239; North, 2005, p. 62).

In this paper, we find that if no one introduces a novel experience in the firm, people engage in interesting work because it stimulates cognitive processes, which improve productivity. If a manager practices adaptive leadership, this manager and the other managers respond by engaging in adaptive work, but they weakly prefer interesting work unless they believe that the adaptive work will improve their understanding of reality and that this improved understanding will increase profits. Managers who are more adept at adaptive work may achieve greater adaptive learning than managers who are less adept. Indeed conditions exist under which the less adept managers may quit the firm because engaging in adaptive work is too costly from their perspectives. However, if the authority figure in the firm is one of these less adept managers, he may choose to fire the manager

This is a work in progress. Please do not cite or quote without permission of the author. 
who is attempting to practice adaptive leadership rather than have the firm improve its understanding of reality.

We reach these conclusions by considering a three-stage game in which managers of a firm make choices about strategies, rules, adaptive work, and leadership. In the first stage of the game, a manager who becomes aware of a novel experience chooses whether to expose the firm to this experience. Exposure to the novel experience creates ambiguity and distress for managers, who experience it as a decrease in individual utility. The experience also stimulates cognitive function up to a point, which increases productivity, but drains cognitive function beyond that point and lowers productivity. Higher (conversely, lower) productivity increases (conversely, lowers) the firm's profits, all other things being equal. In the second stage, each manager chooses her level of adaptive work, which is the work of learning new beliefs so that the novel experience becomes an understandable experience. Adaptive work decreases ambiguity and distress, but requires subjective effort. Adaptive work may increase the profits that the managers expect for the firm if the work increases productivity or improves beliefs. In the last stage the authority figure chooses the firm's rules and strategic variables and managers carry out the authority figure's directives.

\section{An Illustrative Example}

To illustrate adaptive leadership, consider the situation faced by a small group of state utility regulators in the United States in the early 1990s. These utility commissioners, who regulated telephone services in their respective states, came to believe that competition in local telephone service was inevitable and that, as one of them put it, state regulators could either drive the train or be run over by it. This presented an adaptive challenge for state regulators in general who believed in and valued the paradigm of local telephone monopolies and the capacity it gave them to control prices and services.

This is a work in progress. Please do not cite or quote without permission of the author. 
To bring focus to the challenge and expose their colleagues across the country to the reality that the small group of regulators saw, they invited one utility commissioner from each state to a retreat in Keystone, Colorado, where the state commissioners talked with executives, financial analysts, and leading thinkers from the media, computer, and telecommunications sectors about existing trends and the future. Initially many commissioners resisted the new reality, but at the end of the retreat the participants were nearly unanimous in their agreement to work together to examine how they should prepare their individual states and regulatory agencies for this new market structure. The commissioners who participated in the retreat formed task groups, and invited other state commissioners to join them, for the purpose of considering how state regulation needed to change.

As a result of this effort, state regulators were in the forefront of opening local telephone markets to competition and in shaping and implementing the U.S. Telecommunications Act of 1996. Indeed, some state regulatory agency staff spent extended periods of time at Federal Communications Commission after 1996, using their experience to provide guidance on how the federal regulator should craft its rules on local telephone competition.

The rest of this paper is organized as follows. The next section describes our model and then we explain adaptive work, citing empirical literature in neuroscience and psychology to develop our model. We then describe how managers choose their amount of adaptive work when they are exposed to a novel experience. Next we establish conditions under which a manager, who becomes aware of a novel experience, will choose to provide adaptive leadership. In that section we consider the effects of allowing managers to opt out of the adaptive work by engaging in another type of work that we call interesting work. Lastly we examine situations in which people may leave the firm because of adaptive leadership. All proofs are in the appendix.

This is a work in progress. Please do not cite or quote without permission of the author. 


\section{The Model}

We consider a model in which organizations compete for financial resources, which we call revenue. The organizations could be social service organizations such as the Red Cross or Samaritan's Purse competing for contributions, public and quasi-public institutions such as universities or governmental bodies competing for taxpayer funding, or businesses competing for customer demand. To ease exposition, we assume the organizations are firms, but our conclusions could be applied to other types of organizations. We do not specify the nature of the competition for financial resources, except to assume that the market is not perfectly competitive and that profit $\pi$, which we define as the revenue the firm receives from the market minus payments to input providers, such as landlords, materials suppliers, and employees other than managers, is positively correlated with quality and the quality of the managers' beliefs.

The firm is run by managers, one of whom is the authority figure. There is a single production period (we relax this assumption later) and decisions occur in three stages, which correspond to stages in a game. In the last stage, the authority figure chooses the firm's strategy and institutional rules based on the firm's productivity and the firm's managers' beliefs about the state of the world. The authority can perfectly observe both productivity and beliefs. The strategic choices incorporate the authority's technical decisions, such as product choices and output in the case of Cournot competition. An example of strategic choices based on beliefs would be Microsoft's strategic choices in the late 1980s, which emphasized the development and production of the Windows operating system for PCs because most managers did not yet comprehend the future importance of the Internet. Institutional rules are the formal rules that constrain managers' discretion, such as organizational structure, lines of authority, employment, and organization of production. $\mathbf{B}$ is a vector of the managers' individual beliefs about the technological-political-economic environment, including positive beliefs about the way things work and the firm's rivals' strategies, and normative views about the way

This is a work in progress. Please do not cite or quote without permission of the author. 
things should work (North, 2005, p. 2). ${ }^{6}$ Examples include beliefs about customer behavior, technology, how rivals make choices, relationships between rivals and politicians, and the importance of traditions. We normalize each manager's opportunity cost of participating in the enterprise to zero.

The opportunity cost to the firm of its managers not knowing all of reality is the difference between the profits it would receive if it knew reality and the profits it actually receives. Because the managers do not know reality, they cannot observe the firm's potential profits. They also do not know its actual profits ex ante, but are able to observe them ex post. Let $\mathbb{E}(\pi)=\hat{\pi}$ represent the managers' expectations of the firm's profits. We define adaptive learning next.

\section{Theory of Adaptive Learning}

We now consider how the managers change beliefs. In the second stage of the game, managers may undertake adaptive learning, which we define as learning that narrows the gap between existing beliefs and reality, by exploring the meaning and implications of novel experiences that expose the managers to conflicts between beliefs and reality (Heifetz, 1994, pp. 244-245; North, 2005, pp. 66-67). In the case of Microsoft in the late 1980s, observing the potential of the Netscape browser and the Internet would have been a novel experience that did not fit the management's then PC-centric view of computing. Adaptive work was needed to help the company's personnel change their views of the future. Using results from empirical research in neuroscience, neuroeconomics, and psychology, the following discussion describes how the brain processes such experiences

\footnotetext{
${ }^{6}$ It appears that North (2005) includes in his definition of beliefs each player's positive and normative beliefs about other agents' beliefs. Incorporating members' inability to perfectly observe each others' beliefs would be an important extension, but is beyond the scope of this paper. Also, our definition of beliefs is more general than how the term is commonly used in psychology. There the term beliefs includes only the recognition of properties of an object or event. Attitudes towards these properties and towards how a player might behave in response to these properties are referred to as "attitudes" in psychology. Our definition includes both beliefs and attitudes, as they are defined in psychology. See Albarracín, et al. (2005)
}

This is a work in progress. Please do not cite or quote without permission of the author. 
and engages in adaptive learning. We then use this information to construct our model of adaptive learning.

The brain uses two types of processes - controlled and automatic - to handle information. Controlled processes are what we normally think of as analytical processes, which are serial, deliberately evoked, and require subjective effort. Automatic processes reach conclusions based on pattern recognition, involve no feeling of effort, and respond more quickly to stimuli than do controlled processes. (Camerer, Loewenstein, and Prelec, 2005, pp. 11, 16-18, 33; Donald, 1991, p. 365-368) Both controlled and automatic processes can be further subdivided into cognitive and affective processes. Thus there are cognitive controlled, affective controlled, cognitive automatic, and affective automatic processes. Cognitive processes decide what is by, for example, recognizing a car as a car. Affective processes provide attitudes toward experiences and motivate action by, for example, interpreting a car moving toward us as a threat and concluding that we want to get out of the way (Schimmack and Crites, 2005, p. 411). Behavior generally results from the interplay of controlled, automatic, cognitive, and affective processes. (Camerer, Loewenstein, and Prelec, 2005, p. 11)

When someone is expert in her work, she relies largely on automatic processes for decision making (Gobet and Simon, 1996) and her affective processes make decisions without the experience of high levels of emotion or effort (Camerer, Loewenstein, and Prelec, 2005, pp. 16-18). Expertise is developed over time and when someone lacks a reference in an automatic system, she seems flat-footed, responds with greater emotion, and must use controlled processes to develop responses (Camerer, Loewenstein, and Prelec, 2005, p. 16-18, 33). For example, a study of professional securities traders found that traders who were less experienced exhibited greater emotional responses than did more experienced traders when confronted with novel or highly complex situations, such as price or spread trend reversals and increases in price or return volatility. Even experienced traders exhibited high emotions when faced with increases in volatility (Lo and Repin, 2002). These emotional responses represent the traders' reactions to risk and to adaptive challenges. The brain responds negatively to risk - thus the emotional

This is a work in progress. Please do not cite or quote without permission of the author. 
responses in the more experienced traders - but it responds with even greater disapproval to ambiguity - thus the greater responses in the less experienced traders who lacked automatic responses for the situations they faced (Hsu et al., 2005).

Adaptive learning creates and changes automatic processes in that it causes the brain to fashion and accept new patterns and new motivations (Albarracín, et al. 2005, p. 6). Changing automatic processes requires deliberate effort: Controlled processes must exert effort to differentiate specific automatic affect responses, recognize when initial impressions are inappropriate, alter the brain's initial appraisals, and override automatic processes until the new patterns are learned (Gilbert, 2002; Schimmack and Crites, 2005, pp. 403, 424).

Teaching the affective processes in the brain new interpretations requires time, reinforcement, and cognitive effort (LeDoux, 1998, pp. 80, 145; Lo and Repin, 2002). When confronted with an experience, a person initially takes her beliefs about the experience as an accurate reflection of the situation's actual properties. Only subsequently, occasionally, and with effort does she consider other possibilities (Gilbert and Gill, 2002). Repetition is required to develop new mental imprints and the necessary effort competes for mental resources that the person might need for other work (Camerer, Loewenstein, and Prelec, 2005, p. 16-33). Former automatic patterns re-emerge if the stimuli that created the former patterns are reinstated (Camerer, Loewenstein, and Prelec, 2005 , p. 44) or unless the cognitive processing of the novel experiences is repeated and new patterns are re-enforced (Barnes, et al. 2005).

Exposure to novel situations creates ambiguity, which the brain interprets as a negative affect experience (Hsu et al., 2005), and can stimulate controlled cognitive function or shut it down. The novel experience creates tension and the level of tension is positively correlated with the degree of threat that the agent perceives is associated with her belief gap. So, for example, a firm might sponsor brown bag lunches at which employees can hear stimulating speakers on diverse topics. The exposure to non-threatening (or simply mildly threatening), new ideas would stimulate controlled cognitive functions, improving

This is a work in progress. Please do not cite or quote without permission of the author. 
the brain's efficiency (Berlyne, 1960, p. 174). On the other hand, the experience of seeing American car buyers shifting in mass from buying American-made cars to Japanesemade cars in the 1970s and 1980s was hard for the American car manufacturers to comprehend and required adaptive learning about industry traditions, the nature of American car buyers, and how to live with higher gasoline prices. In the extreme the brain's responses, ranging from anger to sadness to fear, to more severe novel experiences can keep controlled cognitive systems from regulating behavior (LeDoux, 1998; Schimmack and Crites, 2005, p. 413; Camerer, Loewenstein, and Prelec, 2005, p. 11). This is called flooding. Thus in total, a novel experience stimulates controlled cognitive function, making it more effective up to a point, beyond which additional stimulation decreases performance and performance may eventually reach zero, i.e., the effect of a novel experience on cognition has an inverted u-shape. (Freeman, 1948; Duffy, 1957; Berlyne, 1960, pp. 50, 163-179; Koob, 1991; Eysenck, 1991; Goleman, 1995, pp. 14, 297-300; Camerer, Loewenstein, and Prelec, 2005, p. 11)

\section{Adaptive Learning Model}

We now formalize our model of adaptive learning. In contrast with other economic research on responses to ambiguity, ${ }^{7}$ we do not explicitly model how ambiguity affects profit expectations. Rather we consider ambiguity to provide a direct, negative effect on utility, which is compounded by a sense of anger, fear, or sadness because the novel experience challenges what the brain considers as known, valuable, and appropriate (Schimmack and Crites, 2005, p. 413). We call the combination of ambiguity and the sense of loss "distress," which lowers utility for those who experience it. With respect to expectations of profit, we consider two scenarios: one in which managers believe that improving beliefs will increase profits and another scenario in which they believe that profits will be unaffected by an improvement in beliefs. This gives us two conditions. Subscripts represent first derivatives.

\footnotetext{
${ }^{7}$ See, for example, Dobbs (1991), Klibanoff, Marinacci, and Makerji (2005), and Halevy and Feltkamp (2005).

This is a work in progress. Please do not cite or quote without permission of the author.
} 
Condition 1. Managers expect adaptive work to have a positive impact on profits, i.e., $\hat{\pi}_{B}>0$.

Condition 2. Managers expect adaptive work to have no impact on profits, i.e., $\hat{\pi}_{B}=0$.

We call Condition 1 the optimist situation and Condition 2 the skeptic situation. We consider two types of experiences: novel experiences and understandable experiences. Novel experiences are those that the manager in question, manager $i$, is unable to make sense of; i.e., they clash with her beliefs $\mathbf{B}^{i}$. An understandable experience is one that makes sense to her, although it is not necessarily true that she correctly interprets the experience. To correctly understand all experiences is to know all reality. Beliefs and understandable experiences are simultaneously defined in that, when a person is exposed to one or more understandable experiences, she does not experience distress, i.e., the experiences are understandable from the person's perspective without engaging in adaptive work, namely, $\mathbf{B}^{i} \equiv\left\{b^{n} \mid D^{k, i}\left(a^{k, i}, x^{k}\right)=0\right\}$. We define these terms next. For simplicity, we assume that all managers have the same beliefs at the start of the game.

In the first stage of the game, a randomly selected manager becomes aware of a novel experience $x^{j}$ and decides whether to practice adaptive leadership by exposing the firm this experience. She might practice adaptive leadership by, for example, raising $x^{j}$ as a topic in management meetings, circulating news articles about it, or organizing projects that cause managers to encounter the novel experience. For simplicity, we normalize the cost of exposing the firm to the novel experience to zero. Adaptive work $a^{j, i} \geq 0$ is able to change experience $x^{j}$ from a novel experience to an understandable experience for person $i$.

This is a work in progress. Please do not cite or quote without permission of the author. 
$D^{j, i} \equiv\left(1-A^{j, i}\left(a^{j, i}\right)\right) x^{j} \geq 0$ is the distress that manager $i$ experiences when exposed to novel experience $x^{j}$, where the value of $x^{j}$ represents its propensity to cause distress. ${ }^{8}$ $A^{j, i}\left(a^{j, i}\right)=[0,1]$ represents the effect of adaptive work on beliefs with respect to removing distress. If there is no adaptive work, then beliefs are unaffected, i.e., $A^{j, i}(0)=0$ for novel experiences. We assume that adaptive work narrows the gap between beliefs and reality, but with decreasing marginal effects, i.e., $A_{a}^{j, i}>0$ and $A_{a, a}^{j, i}<0$. Distress is zero for all understandable experiences and adaptive work on understandable experiences does not affect beliefs, i.e., $A^{k, i}(\arg )=1$ for all understandable experiences $x^{k}$. This is not to say that there are no understandable experiences that people fear, dread, etc. Rather, we focus on distress that occurs when novel experiences indicate that the person's beliefs do not match reality. Adaptive work decreases distress because it adjusts beliefs towards a greater comprehension of reality.

We assume that each manager seeks to maximize individual utility $U^{i} \equiv u(\hat{\pi})-\alpha^{i} a^{j, i}-\delta D^{j, i}$, where $\alpha^{i}>0$ is the constant marginal disutility of the effort required to engage in adaptive work and $\delta>0$ is the constant marginal disutility of distress that results from exposure to the novel experience. Managers differ in the effort required to engage in adaptive work. High types incur a greater disutility of effort than do low types, such that $\alpha^{H}>\alpha^{L}$. Normalizing the number of managers to 1 , we assume there are $h$ high-type managers and 1- $h$ low-type. The authority figure can be either a high type or a low type. For now we assume that managers are able to perfectly observe the authority figure's type. We relax this assumption later. $u(\hat{\pi})$ is the utility that a manager expects from the profits of the firm. We assume utility is increasing in profits received and that agents are risk averse, i.e., $u_{\pi}>0$ and $u_{\pi, \pi}<0$.

The firm's profits are affected by both the beliefs of the managers and their productivity. Let $\tilde{\theta}^{i} \equiv \theta+\sigma\left(D^{j, i}\right)-a^{j, i} \geq 0$ represent the manager's non-negative productivity in

\footnotetext{
${ }^{8}$ We assume for simplicity of exposition that each novel experience takes on a unique value for $x^{j}$.
}

This is a work in progress. Please do not cite or quote without permission of the author. 
carrying out the firm's strategy. $\theta \geq 0$ is each manager's innate capacity to carry out the firm's strategy, engage in adaptive work, and deal with distress. This could be thought of as her capacity of mental energy. For simplicity we assume that all managers have the same innate ability. $\sigma\left(D^{j, i}\right)$ represents the effect of the novel experience on the person's ability to use controlled cognitive processes. $\sigma$ has an inverted u-shape in that lower distress associated with novel experiences stimulates controlled cognitive processes while higher distress lowers the brain's ability to engage in these processes, perhaps even draining the manager's ability to perform logical-deliberative cognitive processes. To express this u-shape, we assume that $\sigma_{D}>0$ up to a level of distress $\tilde{D}>0,\left.\sigma_{D}\right|_{\tilde{D}}=0$, and $\sigma_{D}<0$ for distress levels above $\tilde{D} . a^{j, i}$ represents the direct effect of adaptive work on resources available for technical work and we normalize its marginal effect to -1 . We assume that profit is increasing in the sum of manager productivity at a decreasing rate, i.e., $\hat{\pi}_{\tilde{\theta}}>0$ and $\hat{\pi}_{\tilde{\theta}, \tilde{\theta}}<0$.

Normalizing to zero the utility each manager would receive if no adaptive leadership occurred, each manager's utility maximization problem can be expressed as

$$
\max _{a^{j, i}, x^{j}} U^{i} \equiv u(\hat{\pi})-\alpha^{i} a^{j, i}-\delta D^{j, i}
$$

Subject to:

$$
\begin{aligned}
& a^{j, i} \geq 0 \\
& 1 \geq A\left(a^{j, i}\right) \\
& \tilde{\theta}^{i} \geq 0 \\
& U^{i} \geq 0
\end{aligned}
$$

This is a work in progress. Please do not cite or quote without permission of the author. 


\section{Adapting to Novel Experiences}

Consider the situation where a manager chooses to provide adaptive leadership by drawing attention to the novel experience $x^{j}$. Later we will identify conditions under which the manager optimally chooses to do this. For now we consider how managers respond to the novel experience. We first establish conditions under which it is optimal for managers to engage in a positive amount of adaptive work. We then identify the optimal level of adaptive work. Proposition 1 provides this section's initial result. Conditions 3 through 5 address the constraints in (1).

Condition 3. For manager $i$, the marginal benefit of adaptive work, valued at $a^{j, i}=0$, is less than the manager's marginal cost of effort for adaptive work, i.e., $\left[u^{\prime} \hat{\pi}_{B} x^{j} A_{a}^{j, i}-u^{\prime} \hat{\pi}_{\tilde{\theta}}\left(\sigma^{\prime} x^{j} A_{a}^{j, i}+1\right)+\left.\delta x^{j} A_{a}^{j, i}\right|_{a^{j, i}=0}<\alpha^{i}\right.$.

We call Condition 3 the zero work condition because the manager chooses to not engage in adaptive work when Condition 3 holds.

Condition 4. For manager $i$, the marginal benefit of adaptive work, valued at $A^{j, i}=1$, is greater than the manager's marginal cost of effort for adaptive work, i.e., $\left[u^{\prime} \hat{\pi}_{B} x^{j} A_{a}^{j, i}-u^{\prime} \hat{\pi}_{\tilde{\theta}}\left(\sigma^{\prime} x^{j} A_{a}^{j, i}+1\right)+\left.\delta x^{j} A_{a}^{j, i}\right|_{A^{j, i}=1}>\alpha^{i}\right.$.

We call Condition 4 the fully adapted condition because the manager chooses to fully adapt to the novel experience when Condition 4 holds.

Condition 5. For manager $i$, the marginal benefit of adaptive work, valued at $\tilde{\theta}^{i}=0$ for novel experience $x^{j}$, is greater than the manager's marginal cost of effort for adaptive work, i.e., $\left.\left[u^{\prime} \hat{\pi}_{B} x^{j} A_{a}^{j, i}-u^{\prime} \hat{\pi}_{\tilde{\theta}}\left(\sigma^{\prime} x^{j} A_{a}^{j, i}+1\right)+\delta x^{j} A_{a}^{j, i}\right]\right|_{\tilde{\theta}^{i}=0}>\alpha^{i}$.

This is a work in progress. Please do not cite or quote without permission of the author. 
We call Condition 5 the no-productivity condition because the manager exhausts all of her mental resources on distress and adaptive work when this condition holds.

Proposition 1. When a manager encounters a novel experience and none of Conditions 3, 4, and 5 hold, she engages in positive adaptive work to the point where the marginal utility of her share of the change in expected profit plus the marginal decrease in distress equals the marginal disutility of effort associated with adaptive work, i.e., $u^{\prime} \hat{\pi}_{B} x^{j} A_{a}^{j, i^{*}}-u^{\prime} \hat{\pi}_{\tilde{\theta}}\left(\sigma^{\prime} x^{j} A_{a}^{j, i^{*}}+1\right)+\delta x^{j} A_{a}^{j, i^{*}}=\alpha^{i}$.

Engaging in adaptive work has several effects in the context of a novel experience. One effect is that the agent experiences a decrease in distress equal to $\delta x^{j} A_{a}^{j, i}$, which is beneficial from the manager's perspective. This decrease in distress also changes the agent's productivity by the amount $-u^{\prime} \hat{\pi}_{\tilde{\theta}} \sigma^{\prime} x^{j} A_{a}^{j, i}$, which is positive and increases profits when the distress is so high that increases drain productivity (i.e., when $\sigma^{\prime}<0$ ), or is negative and decreases profits when the distress is low enough that increases stimulate controlled cognitive processes (i.e., $\sigma^{\prime}>0$ ). Adaptive work also directly affects productivity by requiring effort. Lastly, the adaptive work improves beliefs, which weakly improves expected profit by improving strategic choices and rules. Under the optimist situation the manager believes that improved beliefs increase profit, $u^{\prime} \hat{\pi}_{B} x^{j} A_{a}^{j, i}>0$. This leads to Corollary $1 \mathrm{~A}$.

Corollary 1A. When a manager encounters a novel experience, she optimally chooses more adaptive work under Condition 1 than under Condition 2.

Corollary 1A results because increased profit from improved beliefs increases the marginal benefit of adaptive work. Corollary 1B explains that, except when certain constraints in (1) apply, low-type managers engage in more adaptive work than high-type managers.

This is a work in progress. Please do not cite or quote without permission of the author. 
Corollary 1B. When Condition 4 does not hold for a high-type manager and neither Condition 3 nor Condition 5 holds for a low-type manager, the high-type manager optimally chooses a lower amount of adaptive work than does the low-type manager, all other things being equal. Otherwise, the managers optimally choose the same level of adaptive work.

If the fully adapted condition holds for the high-type manager, it also holds for the lowtype manager and both fully adapt to the novel experience. If the zero work condition or the no-productivity condition holds for the high-type manager, then it also holds for the low-type manager. Under the zero work condition both optimally choose no adaptive work and under the no-productivity condition they choose the same level of adaptive work, but the profits of the firm are zero because all mental capacity is consumed by the adaptive work and the distress of the novel experience.

\section{Choosing to Provide Adaptive Leadership}

We now consider the choice that a manager makes with respect to exposing the firm to novel experiences. Assume that the manager in question, which we will call the aware or A-manager, is aware of only one novel experience and chooses whether or not to expose the firm to this experience. ${ }^{9}$ In deciding whether to introduce the novel experience, the Amanager considers how this affects her own expected utility. The novel experience could benefit her if the adaptive work increases the firm's profits by improving beliefs or increasing productivity (by stimulating controlled cognitive processes). However, it is also possible that the novel experience provides significant distress, leading to lower productivity and lower profits. This leads to Proposition 2.

Proposition 2. In the situation where the A-manager knows of only one novel experience, she optimally chooses to introduce the novel experience when her utility from the

\footnotetext{
${ }^{9}$ We leave for future analyses the situation where the manager is aware of more than one novel experiences and chooses which, if any of these experiences to introduce to the firm.
}

This is a work in progress. Please do not cite or quote without permission of the author. 
expected change in profits resulting from improved beliefs and the change in productivity are weakly greater than her costs of distress and adaptive effort. That is to say,

$$
u\left(\hat{\pi}^{*}\right) \geq \alpha^{i} a^{j, i^{*}}+\delta D^{j, i^{*}}
$$

The left hand side of (2) provides all of the potential benefits of introducing a novel experience and can be positive, negative, or zero. The right hand side of (2) is positive whenever adaptive work occurs. If the skeptic situation holds (Condition 2), the Amanager will introduce the novel experience if it will improve productivity, i.e.,

$$
\sigma\left(\left(1-A^{j, i^{*}}\right) x^{j}\right)>a^{j, i^{*}}
$$

Notice that (3) means that in the skeptic situation the A-manager will not introduce the novel experience in the skeptic situation if managers fully adapt, i.e., $A^{j, i^{*}}=1$ because there is no expected benefit to adaptive work.

So far we have assumed that a manager is unable to divert her attention to something else when exposed to a novel experience. We now lift that assumption and consider the situation where the authority figure allows managers to engage in interesting work, which is mentally stimulating work that does not result in learning about reality, but does involve experiences that stimulate controlled cognitive processes. This leads to the following definition.

Definition 1. Interesting work is an activity that stimulates controlled cognitive processes in the absence of a novel experience.

Examples of interesting work might include brown bag lunches in which employees in one part of the firm learn about work in other parts of the firm or discuss something outside their work, such as foreign policy. Google's policy of allowing its developers to

This is a work in progress. Please do not cite or quote without permission of the author. 
devote 20 percent of their time to any project they choose might be an example of interesting work. Interesting work stretches employees by providing them with mental stimulation, but it does not necessarily affect beliefs because it lacks the challenge of a novel experience.

Lemma 1 describes how managers choose to engage in interesting work. For convenience, we let $s^{i}$ represent the experience that stimulates manager $i$ 's interesting work. In general we substitute $s^{i}$ for $x^{j}$ and $\imath^{s, i}$ for $a^{j, i}$ in (1) because interesting work has the same properties as adaptive work, except that it does not affect beliefs and is non-threatening.

Lemma 1. When a manager encounters only understandable experiences, she engages in interesting work where the marginal stimulation of controlled cognitive processes is equal to the ratio of the marginal disutility of distress to the marginal utility of the expected profit stimulated by the greater productivity, i.e.,

$$
\sigma^{\prime}=\frac{\delta}{u^{\prime} \hat{\pi}_{\tilde{\theta}}}>0
$$

The manager engages in interesting work because it improves productivity. She optimally chooses a level of interesting work that is less than the maximum stimulation of controlled cognitive processes because stimulation of these processes is the only positive effect of interesting work and costs of interesting work are strictly positive. (4) ensures that the stimulus for interesting work is non-threatening in the sense that the interesting experience does no more than stimulates her thinking. As it appears from the above examples of interesting work that it is voluntary in nature, we assume that employees are able to choose the magnitude of their stimulating experience and we conclude that they do so according to Lemma 1. This leads to Proposition 3.

Proposition 3. In the situation where interesting work is allowed, a manager weakly prefers interesting work to adaptive work in the skeptic situation. She prefers adaptive work to interesting work in the optimist situation only when the expected benefits of

This is a work in progress. Please do not cite or quote without permission of the author. 
improved beliefs are greater than the difference between (1) the effect of interesting work on productivity, the cost of effort, and the disutility of distress and (2) the effect of adaptive work on these same elements of utility.

The manager weakly prefers interesting work to adaptive work in the skeptic situation because for any novel experience to which she is exposed, she can choose an interesting experience such that (4) applies, which optimizes her cognitive stimulation from her perspective.

In the optimist situation, the expected increase in profits from improved beliefs can tip the scales in favor of adaptive work when (5) holds:

$$
\begin{aligned}
& \left.u^{\prime} \hat{\pi}_{B} x^{j} A_{a}^{j, i^{*}} a^{j, i^{*}}>u^{\prime} \hat{\pi}_{\tilde{\theta}}\left|\sigma^{\prime}\right|_{s^{i}} s^{i} A_{l}^{s, i^{*}} l^{s, i^{*}}-\left.\sigma^{\prime}\right|_{x^{j}} x^{j} A_{a}^{j, i^{*}} a^{j, i^{*}}\right] \\
& -\delta\left[s^{i} A_{\imath}^{s, i^{*}} l^{s, i^{*}}-x^{j} A_{a}^{j, i^{*}} a^{j, i^{*}}\right]-\alpha^{i}\left[l^{s, i^{*}}-a^{j, i^{*}}\right]
\end{aligned}
$$

In (5) the left hand side represents the anticipated effects of improved beliefs on profits and the right hand side represents what the manager gives up by accepting the novel experience over the interesting experience.

Proposition 3 and the subsequent discussion seem to provide dim prospects for adaptive work. This can be in part remedied if the agents have more than one production period and improved beliefs affect profits for more than one period. In considering this multiple production period situation, we apply the findings of Barnes, et al. (2005) that the cognitive processing of the novel experiences must be repeated to have lasting effects. Assume that the adaptive work must be repeated $n$ times, that the improved beliefs improve profits that same amount for $\hat{n}>n$ periods, and a constant discount rate of $r$. As Corollary 3 explains, this improves the profit potential of adaptive work in the optimist situation. The new expected increase in profit from improved beliefs is repeated for $\hat{n}$ periods and the costs are repeated for only $n$ periods.

This is a work in progress. Please do not cite or quote without permission of the author. 
Corollary 3. In the optimist situation when the A-manager knows of only one novel experience, she optimally chooses to introduce the novel experience in more cases in the multiple production period situation than in the single production period situation.

(6) expresses the results for the multiple production period situation. We know that it results in novel experiences being introduced under conditions when they would not be introduced in the single production period situation because the expected additional profits from improved beliefs occur for more periods than do the costs of performing the adaptive work. More specifically, the first term in (6) is simply the benefits of improved beliefs repeated and discounted. The second term in (6) is strictly positive, so (6) will hold any time that (2) holds and also hold under conditions that (2) does not.

$$
\sum_{t=1}^{n} r^{t-1}\left[\left.U_{t}^{i}\right|_{x^{j}, a^{j, t^{*}}}-\left.U_{t}^{i}\right|_{s^{i}, t^{s^{*}}}\right]+\sum_{t=n+1}^{\hat{n}} r^{t-1}\left[\left.U_{t}^{i}\right|_{s^{i}, t^{, i^{*}}}+u^{\prime} \pi_{B, t} A_{a}^{j, i^{*}} a^{j, i^{*}}\right]>0
$$

\section{Casualties of Adaptive Leadership}

In the absence of opportunities for interesting work, novel experiences are imposed on people who may not find it personally optimal to consider the novel experience and engage in adaptive work. For example, a high-type manager has higher costs of adaptive work and so may not wish to consider a novel experience that a low-type manager would want to introduce. This raises the possibility of casualties, which are people who might quit the firm or lose their jobs when novel experiences are introduced. One type of casualty would be a manger whose opportunity cost of being involved with the firm is greater than the utility she would receive if stayed with the firm and engaged in adaptive work. The other casualty would be a low-type A-manager who introduced a novel experience in a firm whose authority figure is a high-type whose utility would be lowered below his opportunity cost were he to allow the low-type A-manager to remain with the firm and engage in adaptive leadership. This takes us to Corollary 2A. Condition 6

This is a work in progress. Please do not cite or quote without permission of the author. 
provides conditions under which a high-type manager would prefer to quit the firm rather than engage in adaptive work.

Condition 6. Being exposed to a novel experience and engaging in adaptive work results in negative utility for high-type managers, but not low-type managers, i.e., $u\left(\hat{\pi}\left(a^{j, H^{*}}\right)\right)<\alpha^{H} a^{j, H^{*}}+\delta D^{j, H^{*}}$ and $u\left(\hat{\pi}\left(a^{j, L^{*}}\right)\right) \geq \alpha^{L} a^{j, L^{*}}+\delta D^{j, L^{*}}$.

Corollary 2A. In the situation where the authority figure does not allow flexibility for interesting work and managers who leave the firm are not immediately replaced, a low-type manager who could practice adaptive leadership and knows of only one novel experience optimally chooses to introduce the experience even though Condition 6 applies whenever the anticipated benefits of improved beliefs plus the effects on productivity of adaptive work for the low-type managers and of losing the high-type managers is greater than the costs of distress and adaptive work, i.e., $u^{\prime} \hat{\pi}_{B} x^{j} A_{a}^{j, L^{*}} a^{j, L^{*}}+u^{\prime} \hat{\pi}_{\tilde{\theta}}\left((1-h)\left(\theta+\sigma^{j, L^{*}}-a^{j, L^{*}}\right)-h \theta\right) \geq \alpha^{L}+\delta D^{j, L^{*}}$.

Practicing adaptive work and accepting casualties of high-type managers increases the productivity of the firm whenever the ratio of stimulated productivity to managers' innate productivity is greater than the ratio of number of high-type managers to low-type managers, i.e., $\frac{\left(\sigma^{\prime} x^{j} A_{a}^{j, L^{*}} a^{j, L^{*}}\right)}{\theta}>\frac{h}{1-h}$.

Corollary $2 \mathrm{~A}$ and the subsequent discussion show that firms with larger proportions of managers who are not adept at adaptive learning will learn less about new realities than will firms that have larger proportions of low-type managers. This could explain why firms in industries that have experienced long periods of stability have trouble adapting when they encounter shocks, such as new technologies or new foreign competition. It could also explain why the surviving firms in such situations sometimes experience significant management change - some incumbent managers don't see the adaptive learning as worth their while and so quit the firm.

This is a work in progress. Please do not cite or quote without permission of the author. 
In some situations the A-manager may be a casualty of her own adaptive leadership. To analyze this situation, we relax one assumption and one normalization. We relax the assumption that managers can perfectly observe the authority figure's type by introducing Condition 7.

Condition 7. The A-manager believes the authority figure is a high-type with probability $p$.

Furthermore, we now express the firm's profits without adaptive work and without interesting work as $\pi^{0}>0$, define the A-manager's utility in the absence of adaptive and interesting work as $U^{0} \equiv u\left(\pi^{0}\right)>0$, and define the A-managers' opportunity cost of participating in the firm as the wage she would receive from her next best opportunity $w \leq U^{0}$. Corollary 2B describes when a low-type A-manager might be a casualty of her own adaptive leadership.

Corollary 2B. In the situation where the authority figure does not allow flexibility for interesting work and the authority figure is a high-type with probability $p$, a low-type A-manager who knows of only one novel experience optimally chooses to introduce the experience and becomes a casualty of practicing adaptive leadership with probability $p$ when Condition 6 holds and $p$ is sufficiently low so that her expected utility after adaptive work, valued where the high-type managers drop out and with probability $1-p$, is greater than $U^{0}-w$, i.e., $\left.(1-p) U^{L^{*}}\right|_{\tilde{\theta}^{H}=0} \geq U^{0}-w$.

Notice that if the A-manager is indifferent between working for this firm without the novel experience and working elsewhere, i.e., $U^{0}=w$, then the A-manager will lose her job with probability $p$ whenever she Condition 6 holds.

Corollary 2B is a shoot-the-messenger scenario and implies that it is dangerous for an Amanager who is easy to fire to engage in adaptive leadership. For example, assume that 
the A-manager is actually a consultant who doesn't know the authority figure very well (and so does not know his type) and who does not have a termination penalty in her contract. The authority figure would simply fire the consultant if the consultant's adaptive leadership caused the authority figure too much distress. The authority figure might actually appear as a hero to the other high-types in the firm.

Finally note that the opportunity for interesting work eliminates the danger of an Amanager being fired for practicing adaptive leadership in our model. High-types can engage in interesting work and so avoid the high distress caused by the novel experience. There is no penalty in our model for managers having divergent beliefs, but it would seem reasonable to believe that if low-types came to understand the world quite differently than the high-types, then there would be problems in the firm because lowtypes and high-types would not be "on the same page." We leave analysis of this situation for future work.

\section{Conclusion}

In this paper we present a model of adaptive leadership that describes the role of an individual in helping an organization confront a novel experience and conform its rules and strategies to new realities. Our model considers the ambiguity and distress that are created by novel experiences and how they motivate managers to engage in adaptive work.

Much work remains. We do not consider how adaptive work might be spread over time by a manager introducing novel experiences in increments. We also do not consider how a manager chooses between novel experiences, should she know about more than one. We also do not explicitly model resistance to adaptive work, identify characteristics that might make one manager more suitable to provide adaptive leadership than another manager, and signal leadership abilities should they be private information. Interesting extensions of this work might include analysis of conditions under which a de novo firm

This is a work in progress. Please do not cite or quote without permission of the author. 
would be more efficient than an existing firm when the environment changes, issues of changing beliefs when firms merge or engage in alliances, and other possible effects of managers within as organization having divergent beliefs. 


\section{Bibliography}

Akerlof, George A. and Rachel E. Kranton. 2000. "Economics and Identity," The Quarterly Journal of Economics, 115(3): 715-753.

Albarracín, Dolores, Blair T. Johnson, Mark P. Zanna, and G. Tarcan Kumkale. 2005. "Attitudes: Introduction and Scope." In Dolores Albarracín, Blair T. Johnson, and Mark P. Zanna, eds., The Handbook of Attitudes, Mahway, New Jersey: Lawrence Erlbaum Associates, pp. 3-19.

Barnes, Terra D. Yasou Kubota, Dan Hu, Dezhe Z. Jin, and Ann M. Graybiel. 2005. "Activity of Striatal Neurons Reflects Dynamic Encoding and Recoding of Procedural Memories," Nature, 437: 1158-1161.

Bass, Bernard M. 1990a. Bass \& Stogdill's Handbook on Leadership: Theory, Research, and Managerial Applications, New York, NY: Free Press.

Bass, Bernard M. 1990b. "From Transactional to Transformational Leadership: Learning to Share the Vision", Organizational Dynamics, 18:19-31.

Berlyne, D.E. 1960. Conflict Arousal and Curiosity, New York: McGraw-Hill.

Blake, Robert R. and Jane Srygley Mouton. 1982. "A Comparative Analysis of Situationalism and 9,9 Management by Principle," Organizational Dynamics, 10(4), pp. $20-43$.

Camerer, Colin F., George Loewenstein, and Drazen Prelec. 2005. "Neuroeconomics: How Neuroscience Can Inform Economics," Journal of Economic Literature, 63(1): 9-64.

Dobbs, Ian M. 1991. "A Bayesian Approach to Decision-making under Ambiguity," Economica, 58: 417-440.

Donald, Merlin. 1991. Origins of the Modern Mind: Three Stages in the Evolution of Culture and Cognition. Cambridge, MA: Harvard University Press.

Duffy, E. 1957. "The Psychological Significance of the Concept of 'Arousal' or ‘Activation,"” Psychological Review, 64:265-275.

Ekvall, G. and J. Arvonen. 1991. "Change-Centered Leadership: An Extension of the Two-Dimensional Model," Scandinavian Journal of Management, 7(1):17-26.

Epstein, Seymour. 1994. "Integration of the Cognitive and the Psychodynamic Unconscious," American Psychologist, 49(8): 709-724.

This is a work in progress. Please do not cite or quote without permission of the author. 
Eysenck, Michael W. 1991. "Anxiety and Cognitive Functioning: A Multifaceted Approach." In Richard G. Lister and Herbert J. Weingartner, eds., Perspectives in Cognitive Neuroscience, New York, NY: Oxford University Press, pp. 314-324.

Freeman, G. L. 1948. The Energetics of Human Behavior. Ithaca, NY: Cornell University Press.

Friedman, James W. 1990. Game Theory with Applications to Economics, 2 ed., Oxford: Oxford University Press.

Fulton, Murray. 2001. "Leadership in Democratic and Participatory Organizations," Canadian Journal of Agricultural Economics, Volume 49, pp. 381-394.

Gilbert, Daniel T. 2002. "Inferential Correction," in Hueristics and Biases: The Psychology of Intuitive Judgment, Thomas Gilovich, D. Griffin and Daniel Kahneman, eds. Cambridge: Cambridge University Press.

Gilbert, Daniel T. and Michael J. Gill. 2000. “The Momentary Realist,” Psychological Science, 11(5): 394-398.

Goleman, Daniel. 1995. Emotional Intelligence. New York, NY: Bantam Books.

Hales, C. P. 1986. "What do Managers do? A Critical Review of the Evidence," Journal of Management, 23: 88-115.

Halevy, Yoram. 2005. "A Bayesian Approach to Uncertainty Aversion," Review of Economic Studies, 72:449-466.

Hamel, Gary. "Management à la Google.” The Wall Street Journal Online, April 26, 2006.

Heifetz, Ronald A. 1994. Leadership Without Easy Answers, Cambridge, MA: Harvard University Press.

Heifetz, Ronald A., and Marty Linsky. (2002). Leadership on the Line: Staying Alive through the Dangers of Leading, Boston, MA: Harvard Business School Press.

Hermalin, Benjamin E. 1998. "Toward an Economic Theory of Leadership: Leading by Example," The American Economic Review, Volume 88(5), pp. 1188-1206.

Hsu, Ming, Meghana Bhatt, Ralph Adolphs, Daniel Tranel, and Colin F. Camerer. 2005. "Neural Systems Responding to Degrees of Uncertainty in Human Decision-Making," Science, 310:1680-1683.

Hunt, J. G. and R. N. Osborn. 1982. "Toward a Macro-oriented Model of Leadership: An Odyssey." In J. G. Hunt, U. Sekaran, and C. Schriesheim, eds, Leadership: Beyond Establishment Views, Carbondale, IL: Southern Illinois University Press, pp. 196-221.

This is a work in progress. Please do not cite or quote without permission of the author. 
Hurwicz, L. 1993. "Toward a Framework for Analysing Institutions and Institutional Change," in S. Bowles, H. Gintis and B. Gustafsson (eds.), Markets and Democracy: Participation, Accountability, and Efficiency, Cambridge: Cambridge University Press, pp. 51-67.

Hurwicz, L. 1996. "Institutions as Families of Game Forms," Japanese Economic Review, 47: 113-132.

Kahn, R. L., D. M. Wolfe, R. P. Quinn, and J. D. Snoek. 1964. Organizational Stress: Studies in Role Conflict and Ambiguity. New York: Wiley.

Klibanoff, Peter, Massimo Marinacci, and Sujoy Mukerji. 2005. "A Smooth Model of Decision Making Under Ambiguity,” Econometrica, 73:1849-1892.

Koob, George F. 1991. "Arousal, Stress, and Inverted U-shaped Curves: Implications for Cognitive Function.” In Richard G. Lister and Herbert J. Weingartner, eds., Perspectives in Cognitive Neuroscience, New York, NY: Oxford University Press, pp. 300-313.

Kotter, J. P. 1990a. A Force for Change: How Leadership Differs from Management, New York, NY: Free Press.

Kotter, J. P. 1990b. "What Leaders Really Do,” Harvard Business Review, May-June, pp. 103-111.

LeDoux, Joseph E. 1994. "Emotion, Memory and the Brain," Scientific American, 270(6): 50-58. **check pages**

LeDoux, Joseph E. 1998. The Emotional Brain: The Mysterious Underpinnings of Emotional Life. New York, NY: Simon \& Schuster.

Lo, Andrew W. and Dmitry V. Repin. 2002. "The Psychophysiology of Real-Time Financial Risk Processing,” Journal of Cognitive Neuroscience, 14(3): 323-329.

North, Douglass C. 1990. Institutions, Institutional Change, and Economic Performance. Cambridge: Cambridge University Press.

North, Douglass C. 2005. Understanding the Process of Economic Change. Princeton, N.J.: Princeton University Press.

Osborn, R. N. and J. G. Hunt. 1975. "An Adaptive-Reactive Theory of Leadership: The Role of Macro Variables in Leadership Research.” In J. G. Hunt and L. L. Larson, eds, Leadership Frontiers, Kent, OH: Kent State University Press, pp. ******

Rotemberg, Julio J. and Garth Saloner. 2000. "Visionaries, Managers, and Strategic Direction," The RAND Journal of Economics, Volume 31(4), pp. 693-716.

This is a work in progress. Please do not cite or quote without permission of the author. 
Robbins, Stephen. 2003. Organizational Behavior, Tenth Edition. Upper Saddle River, NJ: Prentice Hall.

Sappington, David E. M. 1991. "Incentives in Principal-Agent Relationships," The Journal of Economic Perspectives, Volume 5(2), pp. 45-66.

Schriesheim, Chester A., Claudia C. Cogliser, and Linda L. Neider. 1995. "Is it 'Trustworty'? A Multiple-Levels-of-Analysis Reexamination of an Ohio State Leadership Study, with Implications for Future Research,” Leadership Quarterly, 6(2):111-145.

Stogdill, R. M. 1948. "Personal Factors Associated with Leadership: A Survey of the Literature," Journal of Psychology, 25:35-71.

Tooby, John, and Leda Cosmides. 1990. "The Past Explains the Present: Emotional Adaptations and the Structure of Ancestral Environments," Ethology and Sociobiology, 11:375-424.

Van den Steen, Eric. 2005. "Organizational Beliefs and Managerial Vision," The Journal of Law, Economics, \& Organization, Volume 21(1), pp. 256-283.

Van Fleet, D.D. 1975. "Changing Patterns of Significant Authors on Leadership and Managerial Effectiveness," Journal of Management, 1:39-44.

Weber, M. 1964, c1947. The Theory of Social and Economic Organizations (T. Parsons, Trans.), New York: Free Press.

Williamson, Oliver E., and Scott E. Masten, eds. 1999. The Economic of Transaction Costs, London: Edward Elgar Publishing, Ltd.

Yukl, G.A. \& Van Fleet, D.D. 1990. "Theory and Research on Leadership in Organizations." In M.D. Dunnette and L.M. Hough (eds.), Handbook of Industrial and Organizational Psychology, Volume 3. Second edition; Palo Alto, CA: Consulting Psychologists Press, Inc., 147-197.

This is a work in progress. Please do not cite or quote without permission of the author. 


\section{Appendix}

Proof of Proposition 1. Conditions 3, 4, and 5 follow directly from the non-negative adaptive work, upper bound to the effect of adaptive work on beliefs, and the nonnegative productivity constraints respectively. Proposition 1 follows directly from the first order conditions, namely that

$L_{a}=u^{\prime} \hat{\pi}_{B} x^{j} A_{a}^{j, i}+u^{\prime} \hat{\pi}_{\tilde{\theta}}\left(-\sigma^{\prime} x^{j} A_{a}^{j, i}-1\right)-\alpha^{i}-\delta\left(-x^{j}\right) A_{a}^{j, i}-\lambda^{a}+\lambda^{A} A_{a}^{j, i}-\lambda^{\theta}\left(-\sigma^{\prime} x^{j} A_{a}^{j, i}-1\right) \leq 0$ implies $u^{\prime} \hat{\pi}_{B} x^{j} A_{a}^{j, i^{*}}-u^{\prime} \hat{\pi}_{\tilde{\theta}}\left(\sigma^{\prime} x^{j} A_{a}^{j, i^{*}}+1\right)+\delta x^{j} A_{a}^{j, i^{*}}=\alpha^{i}$ where $\lambda^{a}, \lambda^{A}$, and $\lambda^{\theta}$ all equal zero. QED

Proof of Lemma 1. If there is no novel experience, (1) becomes

$$
\max _{l^{s, i}, s} U^{i} \equiv u(\hat{\pi})-\alpha^{i} \imath^{s, i}-\delta D^{s, i}
$$

Subject to:

$$
\begin{aligned}
& l^{s, i} \geq 0 \\
& 1 \geq A\left(l^{s, i}\right) \\
& \tilde{\theta}^{i} \geq 0 \\
& U^{i} \geq 0
\end{aligned}
$$

First order conditions the optimal interesting work include $u^{\prime} \hat{\pi}_{\tilde{\theta}}\left(-\sigma^{\prime} s A_{l}^{s, i}-1\right)-\alpha^{i}-\delta(-s) A_{l}^{s, i}=0$ with gives us $\delta s A_{l}^{s, i^{*}}=u^{\prime} \hat{\pi}_{\tilde{\theta}}\left(\sigma^{\prime} s A_{t}^{s, i^{*}}+1\right)+\alpha^{i} \Rightarrow \iota^{s, i^{*}}$. Then choosing the experience to stimulate interesting work, the first order conditions include $u^{\prime} \hat{\pi}_{\tilde{\theta}} \sigma^{\prime}\left(1-A^{s, i^{*}}\right)=\delta\left(1-A^{s, i^{*}}\right)$ or $\sigma^{\prime}=\frac{\delta}{u^{\prime} \hat{\pi}_{\tilde{\theta}}}>0 . \mathrm{QED}$

This is a work in progress. Please do not cite or quote without permission of the author. 